\title{
Soft Skills Training For Students of Higher Education:
}

\section{Some Initial Observations}

\author{
Mr. Joseph V. Philip ${ }^{1}$, Mr. V. Kannappa Setty ${ }^{2}$, Dr. R. Parthasarathy ${ }^{3}$, \\ Dr. Dorothy P. Rekha ${ }^{4}$
}

Keywords: Soft Skills Training, Higher Education

Recently the authors were assigned to train higher education students (the second year master's and PhD scholars) with soft skills at the Department of Social Work at the Kuvempu University, Shimoga. The department wanted to enhance the students' preparedness into being competent professionals through social skills training as soft skills can enhance their technical expertise.

\section{BACKGROUND}

Based on a review of the training(curriculum) for students of Social Work, we had identified that the higher education programme endows students with the skills to analyse and understand the human problems of their target population they but they still lack the skills to adapt in work settings. Training the students with soft skills can benefit the young professional to excel at the work place by enhancing efficacious interpersonal functioning both with the professional team and with the beneficiaries. Since Social Work addresses issues of injustice in the social fabric, the students run the risk of being influenced by the stress and becoming emotionally burnt. Hence, it is imperative to equip the professional with insight into their personal strengths and limitations. Any professional working in the field of behavioural sciences would benefit from this awareness, not just those in the domain of Social Work. Often insight or awareness and acceptance of personal limitations are found to be factors that enhance resilience in the professional. Hence the authors hope to share their observations in order to encourage other professional and higher education programmes to explore the benefits of the inclusion of soft skills training.

${ }^{1,2}$ PhD Scholar, Department of Psychiatric Social Work, NIMHANS, Bangalore

${ }^{3}$ Senior Professor, Department of Psychiatric Social Work, NIMHANS, Bangalore

${ }^{4}$ Assistant Professor, Department of Psychiatric Social Work, NIMHANS, Bangalore

(C) 2015 I J Philip, V Setty, R Parthasarathy, D Rekha; licensee IJIP. This is an Open Access Research distributed under the terms of the Creative Commons Attribution License (http://creativecommons.org/licenses/by/2.0), which permits unrestricted use, distribution, and reproduction in any Medium, provided the original work is properly cited. 


\section{Soft Skills Training For Students of Higher Education: Some Initial Observations}

The authors used the well known life skills identified by WHO (World Health Organisation) as these skills have tried and tested across populations globally, are easily accessible and can be customised to the group context. In our work, we customised the activities within the Social Work context. Our aim was to build awareness in the young professional which would also translate into empathy towards their benefactors. The method adopted was group activities or individual tasks in a group setting so as to enhance variations in responses apart from their own and the use of role training as group work is a method of Social Work. Hence, they would get to perceive direct applications of the workshop to their work settings.

Based on past experiences, participants in groups are seen to have different skill levels and functioning both throughout and for each skill level. Hence the preparation included reflective activities in group situations to enhance individual learning and games to enhance learning through play which provides flexibility to the authors to choose activities based on the group functioning and learning ability. Learning is the important factor in this process and occurs at two levels; one, at a subjective level and two, as participants observe differences in perception of the group. The learning of each activity is discussed at the end, which assists in the consolidation of learning for the individual and group. Each participant was provided with a handout on the different skills they would be learning in the workshop for future reference. The group session began with an introductory activity to introduce the participants to the authors as the participants were familiar with each other. Subsequently the session took one skill at a time through activity and concluded it with a summary.

Communication: Communication is a process of passing information and understanding. It is an art of transmitting information, ideas, and attitudes from one person to another. It involves a systematic and continuous process of telling, listening and understanding. It is a meaningful interaction between a person and his environment. Thus it is the sum total of directly and indirectly, consciously or unconsciously transmitted feelings, attitudes and wishes.

Two activities were planned as games to understand distortion in communication arising due to the inability to clarify. The first activity focussed at comprehension (selective memory and listening, misinterpretation or incomplete listening) and its inverse relationship to the number of persons. The second activity focussed at understanding differences in individual perception.

\section{Instruction:}

Activity 1: One participant initiates a message and had to whisper the message in the ear of adjacent participant. The participant is not allowed to clarify the message and continues to pass the message until it reaches the last member who reports the sentence aloud.

Activity 2: A story was to be narrated without the use of verbal communication and no clarification. 


\section{Soft Skills Training For Students of Higher Education: Some Initial Observations}

\section{Discussion:}

Activity 1: The discussion focussed at reasons for the distortion of the message.

Activity 2: The focus of the discussion was the challenges of explaining and obtaining exact information.

Observation: In activity 1, participants were observed to deliberately alter the statement to ensure a changed message. This was largely due to the participant's familiarity to the outcome of the activity and hence performing stunts as observed in children once they master a skill.

In the second activity the group was keen about the entertainment level of the activity and less on the learning. These observations were also utilised in the discussion.

Conclusion: The participants appeared to be familiar with the difficulties of distortion in communication so the participants were educated on the utility of the skill in daily practice and specifically at work places.

Interpersonal Relationship: Relationships are an important source of social support but not all relationships are the same and some may have repercussions where it would need to end (WHO, 1997). Interpersonal Relationship skills help individuals to relate in positive ways with others to make, keep and end friendly relationships. These skills enhance mental and social wellbeing. A play activity was planned for the group with goal to harness team support in accomplishing the task.

Instruction: The group was split into three and volunteers of each team were instructed to accomplish as task with their respective group. The team was provided varying instructions from full support, partial support and resistance.

Discussion: Involved identifying factors that contributed to building co-operation and coordination with various members.

Observation: The activity involved the cooperation of team members and skills of understanding, listening actively and supporting the team. The group that provided no resistance appeared to be purposive at finishing the task at hand while the group that resisted displayed truancy. The group that displayed partial resistance was ambivalent at the levels of challenge they were to pose and displayed empathic skills at the turn around point.

Conclusion: The participants gained insight into the challenges and flexibility required to work along with the varied demands.

Self-Awareness Skill: Self-Awareness is awareness of one's thoughts, emotions, feelings and the personal ability to control it. Knowledge of one's immediate and long term needs, wants, desires, wishes and its intensity contribute to personal well-being or happiness. This is awareness of mood and the thought behind the mood. Thoughts are also involve beliefs about oneself and 


\section{Soft Skills Training For Students of Higher Education: Some Initial Observations}

they can be categorised into "Projected Self", "Real Self" and "Ideal Self". An effective manner of understanding or building awareness of self is knowledge of strengths and weaknesses. These can be easily evaluated over particular situations and people through SWOT (Strengths, Weaknesses, Opportunities and Threats). Periodically analysis is recommended esp., when important decisions are to be made.

The following activity was based on helping the participants building aware of thoughts, emotions and behaviours being within one's control. Instruction: The participants were asked to use the SWOT (Strengths, Weaknesses, Opportunities and Threats) analysis to categorise their abilities and beliefs.

Discussion: The discussion was based on understand personal limitations, accepting strengths, communicating realistic expectations, respecting themselves - through providing space and time both to self and others.

Observation: The participants needed more time to grasp these reflective concepts of real self and ideal self.

Conclusion: The participants realised potential areas to enhance and improve in their personal lives.

Empathy: "The ability to imagine oneself in another's place and understand the other's feelings, desires, ideas, and actions." - Carl Rogers. The use of empathy is an important technique in counselling.

Two play activities were planned to help participants identify with the experiences of others.

\section{ACTIVITY 1:}

Instruction: The group was divided to form pairs and one volunteer was suggested to perform their partner's role and discuss its challenges.

Discussion: The challenges in the task and the alternatives sort were discussed.

\section{ACTIVITY 2:}

Instruction: Participants were asked to suggest tips to fellow participants to enrich their lives and the suggested participant was asked to respond the advice. This was to continue until consensus was arrived.

Discussion: The discussion focussed at the participants understanding of both the individual's behaviour and choices.

Observation: Activity 1 the group didn't seem to grasp the instruction as some participants were observed to use the opportunity to mock their partners and their behaviour publicly. Activity 2 was observed to have the participants discuss suggestions which were not realistic and 


\section{Soft Skills Training For Students of Higher Education: Some Initial Observations}

participants did not appear to be comfortable to share personal experiences for fear of being mocked.

Conclusion: The participants became aware of the obstacles in dealing with others emotions and its need in work situations especially with benefactors.

Creative thinking skills: Creativity is the ability to imagine or invent something new. Creativity is not the ability to create something out of nothing rather the ability to generate new ideas by combining, changing, or reapplying existing ideas. An individual activity to develop creative thinking by practice was chosen.

Instruction: Each individual was asked to use paper to create different materials apart from its usual use/s. The uses have to be may be fanciful but has to be practical.

Discussion: The discussion focussed at the process which helped the person arrive at the innovative thinking.

Observation: The participant appeared comfortable to showcase their ability. This could possibly be due to the high competitive spirit amongst the group display their ability to think differently.

Conclusion: The participants were able to harness their repertoire for ideas that they executed.

Critical Thinking: Critical thinking is a manner of thinking that involves reason, reflection, responsibility and skill to decide on what to believe or do. In short it evaluates risks and benefits of the problem at hand. Critical thinking enhances skills of questioning, gathering relevant information, efficiently and creatively sorting through information, reasoning logically and arriving at reliable and trustworthy conclusions that enable individuals to live and act successfully.

A reflective individual activity was chosen where the participants evaluated the risk and benefits of their personal choice.

Instruction: The personal reason/s to choose the MSW course and what factors influenced the decision was to be critically evaluated.

Discussion: The participants shared their limitations in arriving at the decision and the kind of information that they relied upon to make this decision. The discussion furthered into an understanding how decisions would continue to have flaws due to ignorance and having complete knowledge is not pragmatic.

Observation: The participants provided socially desirable responses and were keen to understand the process of decision-making. While the participants were engaged in the activity they appeared conscious about themselves to share openly before the group. 


\section{Soft Skills Training For Students of Higher Education: Some Initial Observations}

Conclusion: The participants got to understand their subjective bias that hampered objective evaluation.

Managing Stress: Stress is a condition or feeling where an individual perceives "demands to exceed personal and social resources beyond their personal ability to mobilize". The characteristics of stress are; it has physical and emotional effects; emotions thus created may be positive or negative feelings; insufficient stress is seen to cause boredom while excessive stress may lead to breakdown; and stress cannot be eliminated rather managed. Hence, maintaining an optimal level of stress is ideal.

Two activities were planned the first was a reflective group activity and the second was a reflective individual task.

\section{ACTIVITY 1}

The activity had two objectives:

1. To realize that stress in universal and ongoing.

2. To identify the emotional reactions towards stress and be able to plan on managing stress. Instruction: A reflective exercise was chosen where the group was to stand around in a circle formation and pass a ball. The participant's name had to be called out before passing. The ball had to be passed to all members before the person who initiated the game receives the ball. The game would restart if at any point the wrong names were called, ball was passed to the wrong person or if the ball was dropped. Once the group has mastered this task then it was repeated with 5 balls being passed around simultaneously. Discussion: The time duration was compared between one ball being passed and the when five were being passed. The reactions of the group members while mistakes occurred and how they could identify this game with real life situations were explored. ACTIVITY 2:

The objective was to facilitate muscle relaxation.

Instruction: The instructions were to sit in a comfortable quiet room. Close the eyes, make a tight fist, hold for 5 seconds, and gradually relax the hand. This was to be repeated 3 times. Attention was to be drawn to the different sensations of tension and relaxation. The above steps were to be repeated with all muscle groups i.e., arms, shoulders, chest, abdomen, back, hip, thighs, lower legs and feet. In the discussion the experiences of the body and mind during this exercise is elicited.

Discussion: Focussed at the group sharing their personal experiences about the exercise. And in the discussion the group considered the benefits and the situations where the exercise may be practised. 


\section{Soft Skills Training For Students of Higher Education: Some Initial Observations}

Observation: Activity 1 the group was found to stunt when one ball was part of the group and with frequent re-starts the group participants were frustrated with members that broke the rules. The group appeared overwhelmed and eager to finish the task when five balls were introduced. This also made the participants display their annoyance more openly with persons that faltered.

In activity 2 the group were spontaneous and eager to share their experiences of the exercise. They were equally participative in the discussion with personal reflections. The participants it appeared to find the activity meaningful; it could possibly be due to the participants relating the practise similar to yoga.

Conclusion: The influence of stress on the physical body and the experience of calmness as a mind state were experienced.

Coping with Emotions: Management of emotions is found to be equally important for success and happiness, as intelligence. While intelligence capacity may not be altered, emotional maturity can be improved.

The aim of the activity was to identify emotions.

Instruction: In a reflective activity the participant was asked to identify the emotions and reactions experienced in a situation of conflict.

Discussion: Focussed at the effect of emotions on the outcome of the situation; evaluating if similar patterns were visible in other situations and building an understanding on the styles of coping. The effect of emotions on interpersonal relationships and challenges in identifying emotions were discussed.

Observation: The participants shared varied personal reactions to the situations which brought about alternative perspectives. The participants had differing loyalties forming alignments and these not necessarily based on gender.

Conclusion: The participants were able to identify emotions and how it clouds judgement and ability to perceive alternatives.

Problem-Solving: Involves defines the challenges or stresses as problems to be solved or goals to be attained. Defining the problem helps in bring clarity and not just solving the problem alone.

The activity identified had two objectives;

1. To help the participants understand how intensity varies with the same problem.

2. To understand the complexity of the problem determines the approach and the time required.

Based on the above objectives two activities were planned. 


\section{Soft Skills Training For Students of Higher Education: Some Initial Observations}

\section{ACTIVITY 1:}

Instruction: The group game involved two groups where one group was provided all varieties of thread material and the second group was to observe the first group as they tied different types of knots. Once the second group received the knots they were given two minutes to untie the knots.

Discussion: The participants shared about the methods used to tie and untie the knots. The discussion focussed at deconstructing the process in smaller parts of problem solving viz., identification of the problem, the choosing from the various alternatives and weighing out merits and demerits. It also focussed at the addressing how the alternatives would change based on the intensity of the problem and the understanding of the problem.

\section{ACTIVITY 2:}

Instruction: In another play activity participants where to line up in pairs with partners facing each other. A long thin, light rod is placed the index fingers of the participants and asked to lower the stick to the ground. All participants fingers are to be in constant contact with the rod at all times. If any participant is found not touching the rod, the task is to be restarted at shoulder height.

Discussion: The perception of the problem, intensity and resources harnessed were explored before each stage of planning. The role of leadership, other roles, co-ordination, assessment, and the experiences while execution of the plans were discussed. Finally, the application of this in the field of social work was brainstormed.

Observation: In activity 1 the participants were competitive and tried making it difficult for the others to remove the knots and the second group broke rules of the activity to achieve their goal.

In activity 2 the group had a critical leader who was rigid and focussed at the outcome while the second group had no person willing to own up the leadership while their discussion revealed cohesion. In terms of outcome the first group was closer to achieving the goal than the second.

Conclusion: The participants realised the use of problem solving components that were being utilised daily in an unconscious manner. The clarity in the activity lead to the participants being able to evaluate effectively.

Decision-Making Skills: Decision Making is the internal (mental) action of identifying alternatives and options and choosing from among them. It is a commitment to do or to refrain from doing something. The goal of the activity was to focus on recognizing existing decision making skills that each participant possesses.

Instruction: A group activity involving a crisis situation was provided and the groups were to arrive at a decision in twenty minutes. The group was to unanimously agree before the decision was to be arrived. 


\section{Soft Skills Training For Students of Higher Education: Some Initial Observations}

Discussion: Focussed at the ability of participants who had differing views to convince the others that their ideas were better. The process of the decision making, experience when others shared their ideas, easy and flexibility to change were the points of review.

Observation: The groups were able to arrive at a unanimous decision within 20 minutes with no pressure to make a decision. The groups did appear to have one or two dominant persons and the rest of the participants agreed with their views. There appeared to have no challenging or conflicts while arriving at the decision.

Conclusion: The participants got to understand differences in perception and limitations/ inadequacy of information compelling them to analyse a course of action.

\section{OUR UNDERSTANDING}

The Master of social work discipline utilizes the understanding of various disciplines in working towards human development and addressing injustices in the society. The programme in India while following a similar content universally through universities and departments has varied levels of preparedness. Often the competency of the professionals trained from these institutes is attributed to individual capacities. At the National Institute of Mental Health and Neuro-Sciences (NIMHANS), Bangalore a deemed university which offers doctoral programmes in Social Work, students from various institutes are represented. Of these students having cleared a national exam varying preparedness is observed which we attribute to the lack of certifying authority who overseers the professionals in their training and practice. Thus, we agree that higher education students tend to leave their programmes without preparedness in leading a competent life (Rekha, 2005).

According to Windsor and colleagues (2012) the main function of Higher Educational Institutions is to produce skilled and knowledgeable personnel who are able to not only function with minimal guidance but also to contribute effectively to the hiring organizations. Many studies have indicated that most Higher Education Institutions have somewhat similar course content and thrived at producing students with good academic achievement. But what differentiated them from one another is their ability to develop knowledge workers with the right employability skills or 'soft skills' such as communication, problem-solving, interpersonal and other skills deemed important as the foundations by which they require to function at work regardless of the nature of employment.

Soft skills apart from its utility at work place contribute to enhancing the person with life skills. These have a vast application and hence provides easy access to train personnel. In our endeavour authors focused at defining the area to higher education students of professional setting.

Students of higher education are generally found to be trained in technical skills (hard skills) and found wanting in soft skills without which, the student is regarded as incompetent in the above 


\section{Soft Skills Training For Students of Higher Education: Some Initial Observations}

skill. Soft skills can be regarded as the additional generic skills which are beneficial student. Each of the above soft skills have been explained for training of students of higher education.

The skills chosen were active and experiential so as to create a dynamic teaching and learning process. Active learning (viz., brainstorming, group discussions, debates and games) and experiential learning (games and role-play) were used. Life skills lessons also included homework assignments that extend their analysis and practice of life skills to their lives at home and in their professional field work training.

\section{CONCLUSION:}

While the value of the programme is endorsed universally an assessment was not performed to under the transfer of training. Therefore authors state two aspects firstly the need for technically trained personnel needing soft skill training as part of curricula, customized to their programme so that Higher Education leads to skilled and knowledgeable personnel who are able to not only function with minimal guidance but also to contribute effectively to the hiring organizations. Secondly, to identify tools to assess efficacy of training transfer thereby to improvise.

In our training we focused at three components concept, application to self and professional application. The methods used were lecture, activity and play. Of the goal was to get the students to learn through reflection.

\section{REFERENCES:}

Rekha, D. P., (2005). Enhancing Practice Skills of Social Work Trainees through a Short-term Participatory Training Programme - A Feasibility Study, Unpublished Thesis, NIMHANS, Bangalore.

Windsor, C., Douglas, C., \& Harvey, T. (2012). Nursing and competencies - A natural fit: The politics of skill/competency formation in nursing. Nursing Inquiry, 19(3), 213-222.

Encyclopaedia Britannica (2011 online edition). Life skills, World Health Organisation, 1997. 